\title{
ARTICLE
}

\section{Climate biocapacity of Mongolia and its change}

Natsagdorj L. *, Munkhbat B. and Gomboluudev P.

Information and Research Institute of Meteorology, Hydrology and Environment, National Agency for Meteorology and Environmental Monitoring, Ulaanbaatar, Mongolia

ARTICLE INFO: Received: 17 May, 2019; Accepted: 01 Aug, 2019

\begin{abstract}
This paper has looked into the estimated results of climate biocapacity in Mongolia. The soil moisture supply was assessed through annual precipitation, Shashko's humidity coefficient, Selyainov's heatmoisture coefficient and Ivanov-Mezentsev climate biological productivity index. Finally, their long-term trends have been considered as well. The results are consistent with vegetation zones, summer mean pasture yield and existing arable farming region in the country. Therefore, the results are applicable in Mongolia's conditions. Also, the heat supply during growing season is estimated by daily average temperature, which fluctuates from 5 and $10^{\circ} \mathrm{C}$ in spring and autumn respectively, the sum total of effective and active temperature. Since 1960, the growing season in the country has lengthened by 3 weeks and the sum of active temperature above $10^{\circ} \mathrm{C}$ has increased by $80-90^{\circ} \mathrm{C}$, although the moisture supply of vegetation is weakening and moreover, climate biocapacity is decreasing.
\end{abstract}

Keywords: Climate biocapacity; heat supply; moisture supply; arable farming region; humidity coefficient;

\section{INTRODUCTION}

The impact of weather and climate on agriculture, in particular on crop yield, quality of product and operational costs is great. Moreover, it is also important to review the arable farming regions, identify where specific crop varieties can be grown and what kind of new crop varieties could be introduced with due consideration of the changing climatic conditions.

In order to use potential climate resource in local area in terms of appropriate ratio, what is needed is to assess climate biocapacity as expressed by rationality of natural components, which defines the biological production of the land [1]. The climate biocapacity $(\mathrm{CBC})$ has to show biological production with certain level. On the other hand, $\mathrm{CBC}$ can be expressed by ratio between heat and humidity, which could represent the $\mathrm{CBC}$ of the natural landscape.

The biological productivity of vegetation organism is biomass quantity (ton/ha and centner/ha), which is calculated per unit time (mostly year and growing season) and unit area (ha). The humidity, heat, soil fertility, arable farming intensification and biological characteristics for a particular crop etc. are the main factors for biological productivity of the natural landscape [2]. 
The coherence between crop yield (productivity) and $\mathrm{CBC}$ can be defined as follows: Ecological productivity of agricultural crops in a particular development stage is defined by nutrients used in vegetation, which exists in liquid substance form. An accessible soil nutrient substance is defined by heat-humidity factors, which are the results of interaction of microorganism in the soil, the speed of biochemical reaction of photosynthesis and soil moisture. Not only heat-humidity factors, but soil agro-physic and agro-chemical properties too have an effect on accessible soil nutrient substance.

Accordingly, a comparison of the northhumidity zone with south-semi dry zone, which has high vegetation heat supply, shows that their soil nutrient substances are roughly the same. It could be even higher if conditions are favourable. Therefore, agriculture crop yield is consistently dependent on CBC.

The effects and benefits of mineral and fertilizer is defined by the rational condition of heat-humidity during usage of soil nutrient substances. On the other hand, the fertilizer used in the rational heat-humidity condition, easily converts to soil liquid form, which can be used by the plant. Therefore, the soil nutrient substance is better produced as a result of biochemical and microbiological process in an area that has high heat supply, even in identical natural zones. Hence, an assessment of the climate bio productivity at local level is important for potential application of the land biological productivity.

Scientist and experts of the former USSR had conducted initial research looking into the possibility of developing modern arable farming in Mongolia [3]. At the end of 1950, one of Mongolia's first agronomists A. Khüchit and other Mongolian experts together with scientists P. A. Javoronkov, M. A. Lysenko, P. Andryechuk, E. G. Sokratov, L. I. Dubrovskaya from the Soviet Union developed 1.783 thous. ha of virgin land for growing cereals, vegetables, fruits and animal feed. After which another 400 thousand hectares of land was developed for arable farming during the initial stage of the "Atar Ayan" (Virgin Land Reclamation) program in 1959-1961[4].

The climate resource for agriculture was initially defined by again Mongolia's first meteorological scientist B. Jambaajamts in 1970, which can be found in his monograph "The climate zone classification on territory of the Mongolian People's Republic" [5]. He had carried out climate zone classification to define "dryness degree", which estimated heat supply based on sum of active temperature higher than and moisture supply using the forumula $D I=\sum(E-e) / P$. The results of his research have been reflected in reference documents and also the atlas of agriculture of Mongolia [6, $7,8,9,10]$. However, only general indicators of climate resource for agriculture were then covered in his work.

A dynamic-statistic model "Weather-soilyield" was developed by former Soviet scientists O. D. Sirotenko and E. V. Abashina. Mongolian scientits S. Sangidansranjav and D. Dagvadorj had configured this model under Mongolian conditions and had attempted to produce 1-2 month cereal yield forecast in 1985 [11].

D. Dagvadorj has analyzed the trends of cereal yield and had classified arable farming region based on the variance of summer wheat yield such as relative stable yield region (Khövsgöl-Bulgan sub regions), meduim stable (Selenge basin-eastern part of ArkhangaiÖvörkhangai-northern part of Kentii), medium instablity (northen part of Töv aimag) and high instablity yield region [12].

S. Sangidansranjav, Sh. Bayasgalan and D. Erdenetsetseg et al., have used "Weather-soilyield-3" dynamic-statistic model to estimate the potential yield of summer wheat under rational condition of irrigation and fertilizer application. The yield is 3-4 times higher than the normal condition in the Selenge basin area [13] (Figure 1). According to their findings, summer average wheat yield is higher 10 centner/ha in Orkhon-Selenge sub region of central arable farming region and 5-10 centner/ ha as compared to other regions. 


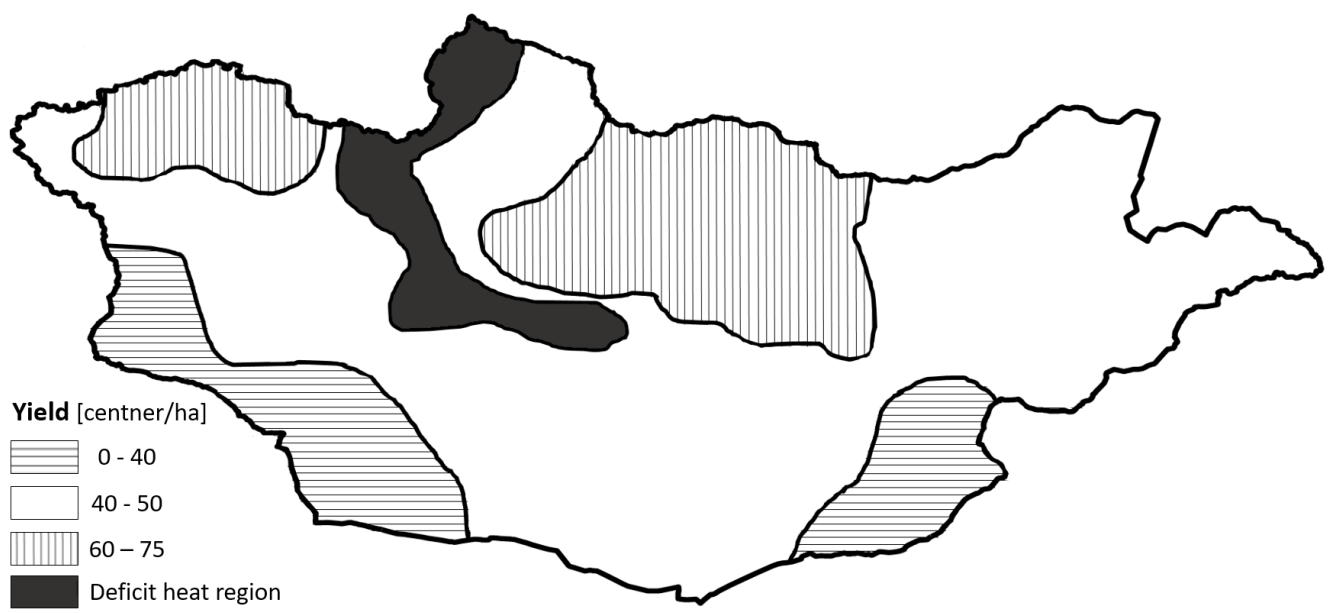

Figure 1. Potential yield amount during most rational condition of soil moisture and nitrogen fertilizer (S. Sangidansranjav, Sh. Bayasgalan, D. Erdenetsetseg et al., 1989)

A Mongolian scientist Sh. Bayasgalan had estimated the potential yield of summer wheat and potato using DSSAT3 model based on 36 meteorological stations in arable farming region in the year 2000. He had likewise made an impact assessment under different climate change scenarios.

B. Bayarmaa had attempted to estimate and assess climate biological effective index using the Selyaninov heat-moisture coefficient (named as "ГТК -гидротермический коэффициент" in Russian books), the N. N. Ivanov's humidity coefficient (ratio between annual precipitation amount and surface evapotranspiration). The study covered 20 years of meteorological data collected from different locations, such as the western soums of Selenge aimag from 1994 to 2013 and compared results with measured crop yields [14].

O. Mönkhdulam, E. Avirmed and D. Sainbayar, researchers with the Institute of
Geography and Ecology of the Mongolian Academy of Sciences, have estimated climate biological effective index using $G$. T. Selyanninov's heat-moisture coefficient, N. N. Ivanov's humidity coefficient and climate biocapacity (estimated by Formula (4) as mentioned before) using Shashko's method based on data collected from some meteorological stations and posts from 2000 to 2014, as well as satellite data, and finally they produced maps of Mongolia [15]. The value of heat-humidity coefficient has been calculated with higher value depending on the difference between satellite data and ground observation at meteorological stations, and subsequently, future estimation was with low confidence. For example, according to the existing rules, local biological capacity and climate biocapacity should be consistent with rational condition of heat-humiditym but its value is higher in the high mountainous zones, where the sum of active temperature is never higher than $10^{\circ} \mathrm{C}$. 
A former Soviet scientist P. I. Koloskov was the first scholar to introduce the new term 'climate biocapacity' in science and practice in 1962 [16]. He had formulated that climate biocapacity must express land biological productivity, which depends on climate factors such as air temperature, humidity and radiation insolation. He assessed the $\mathrm{CBC}$ using rating score over the territory of former USSR. The ratio between annual precipitation and sum of deficit humidity (surface evaporative capacity), $\quad\{\mathrm{P} /(\mathrm{E}-\mathrm{e})=32\}$ was considered by one unit. Then local area $\mathrm{CBC}$ is divided by 32 and is measured by scoring points. According to his assessment, $\mathrm{CBC}$ was established as twice higher than in the western part of Europe of the former USSR, 2-3 in north Kavkaz, 6 in the Black Sea region, up to 2 or a little less in the Altai region, 1.5 in western Siberia and its remaining part, and less than 1 in eastern Siberia.

S. A. Sapojnikova [17] proposed climate rating, CRB (originated from Latin word "bonitas" and became a common term called as "bonitet") of the countries in the Europe part of the former USSR and Eastern Europe in 1979 as follows:

$$
C R_{B}=\varepsilon \sum T_{>10^{\circ} \mathrm{C}}
$$

Where, climate bonitet $\mathrm{CRB}$ is equal to mean wheat yield in local area of appropriate resource for heat-humidity condition, $\varepsilon$-is bonitet order of humid-dry climate condition and is defined as:

$$
\varepsilon=-1.7 K_{\varepsilon}^{2}+3.7 K_{\varepsilon}-0.28
$$

Where $K_{\varepsilon}$ is Sapojnikova humidity coeffiecent and expressed as the following formula:

$$
K_{\varepsilon}=\frac{0.5 P_{\mathrm{X}}+P_{\text {Д }}}{0,18 \sum T_{>10^{0} \mathrm{C}}}
$$

This means that the sum of cold and warm season precipitation $\left(P_{C} P_{W}\right)$ is divided by annual potential evapotranspiration estimated by the Budiko method $0.18 \sum T_{>10^{\circ} \mathrm{C}}$ However, snow in winter in Mongolia is not heavy and even melts while the soil is still frozen. It is therefore assumed that the first number of a numerator could be left or replaced by autumn precipitation, which represents spring premoisture.

Today, method developed by a former Soviet scientist D. I. Shashko is widely applied for assessing the climate rate [18, 19]. This method is based on estimation of potential as well as real wheat yields for agricultural climate rate. The real yield is the mean yield under normal agro technical condition and potential yield is the estimated crop yield using potential heat supply under normal humidity condition.

D. I. Shashko's relative value of CBC is estimated over a large area as follows:

$$
C B C=K_{\mathrm{p}} \frac{\sum t_{>10^{\circ} \mathrm{C}}}{\sum t_{c}}
$$

Where, $K_{\mathrm{p}}$ - coeffiecient for growth rate, which is defined by coefficient $\left(M_{d}\right)$ of humiddry climate condition, $\sum t_{>10^{\circ} \mathrm{C}}$ sum of active temperature of daily mean during growing season, and $\sum t_{C^{-}}$reference value of active temperature. This reference value could be taken differently when comparing $\mathrm{CBC}$ in actual local area with an area that is under arable farming. For example, threshold value is taken at $1000^{\circ} \mathrm{C}$ in the northern region, $1900^{\circ} \mathrm{C}$ as mean value over Russian territory and $3100^{\circ} \mathrm{C}$ as rational climate condition of mid-latitude region. The growth rate coefficient $K_{\mathrm{p}}$ in formula (4) means the ratio between yield in local moisture condition and maximum yield in rational moisture condition and the formula is expressed as follows:

$$
K_{\mathrm{p}}=\log \left(20 M_{d}\right)
$$

Where, $M_{d}$ is the Shashko's humidity 
coefficient, which defines the ratio between annual precipitation (or during growing season) and sum of daily mean of air deficit humidity.

$$
M_{d}=\frac{\sum P}{\sum(E-e)}=\frac{\sum P}{\sum d}
$$

When Shashko's humidity coefficient, $M_{d}=0.5$ condition is satisfied, plant moisture supply is at the rational level. At this moment $K_{\mathrm{p}}$ takes 1 value. On the other hand, coefficient of humid-dry condition does not exceed the ranges between 0.10 and 0.20 , while the coefficient of growth rate decreases. Therefore, arable farming in such an area and region cannot be developed without an irrigation system.
In order to compare and assess the agricultural bio climate productivity, CBC is needed to define for scoring purposes as proposed by D. I. Shashko. He offered 2 options for estimating man climate bio productivity $\left(B_{C}\right)$ and productivity of highest rational plant growth $\left(B_{C \text { (rat) }}\right)$.

$$
\begin{aligned}
& B_{C}=K_{P} \frac{\left(\sum t_{>10^{\circ} \mathrm{C}}\right) \cdot 100}{1000}=55 \cdot C B C \\
& B_{c \text { (rat })}=K_{P} \frac{\left(\sum t_{>10^{\circ} \mathrm{C}}\right) \cdot 100}{3100}=0,6 \cdot B_{C}(8)
\end{aligned}
$$

Where the denominator of formula (7), it could be calculated 1900 instead of 1000 . Based on estimation using the formula, CBC is categorized as follows (Table 1).

Table 1. Assessment scale of biological productivity

\begin{tabular}{|c|c|c|}
\hline Biological productivity & CBC & $B_{C}$ \\
\hline Much less & $<0.8$ & $<40$ \\
\hline Less & $0.8-1.2$ & $40-60$ \\
\hline Little less & $1.21-1.6$ & $61-85$ \\
\hline Meduim & $1.61-2.2$ & $86-120$ \\
\hline Above medium & $2.21-2.8$ & $121-155$ \\
\hline High & $2.81-3.4$ & $156-190$ \\
\hline Very high & $>3.4$ & $>190$ \\
\hline
\end{tabular}

Mongolia's arable farming region is located close to the northern part of the cold region arable farming zone. Therefore, it is possible to use the threshold value as 1000 .

Among the widely used physical-statistical model for CBC assessment, dynamicstatistical model "Weather-soil-yield", which was developed by O. D. Sirotenko and E. B. Abashina, was widely used in the 1980s [20]. This model has modules such as accounting crop biological characteristics, weather factors (heat and humidity), soil fertility and agro technical level. The model simulates CBC1 assessment based on actual soil moisture, $\mathrm{CBC} 2$ under condition of enough moisture or rational moisture, $\mathrm{CBC} 3$ under soil rational fertility and $\mathrm{CBC} 4$ under rational soil moisture and fertility. A key advantage of this model is it makes is possible to estimate biomass under and above the ground in each crop growing stage, as well as project agricultural productivity and change of arable farming region under future climate change scenarios. Simulated dry biomass above ground or yield amount is considered as CBC. The model was tested for wheat, with $70 \%$ of the model for assessing assimilation spend for above ground growth and remaining 30\% for growth of root system.

One of the widely used indicator variables is climate biological productivity index TK (also better known as climate biological effectiveness), which was developed by a former Soviet scientist N. N. Ivanov in 1948 $[21,22]$.

$$
\mathrm{TK}=\mathrm{T}^{*} K_{y}
$$

Where $\mathrm{T}$ equals the sum of active temperature value divided by $100, K_{y}$ - Ivanov 
humidity coefficient.

$$
K_{y}=\frac{P}{E_{M}}
$$

Where $P$ is annual precpitation and $E_{M}$ is annual potential evapotranspiration and it is estimated using the following formula as proposed by Ivanov.

$$
E_{M}=0.0018(25+T)^{2 *}(100-f)
$$

Where $\mathrm{T}$ is the monthly mean air temperature in ${ }^{\circ} \mathrm{C}, f$ is the monthly mean relative humidity, In percentage. However, the $E_{M}$, potential evapotranspiration, suggested by V. S. Mezentsev could be estimated using the formula $\left(0.2 \sum T_{>10^{\circ}}+306\right)$ in Siberian condition [23]. Here, the 306 value is contant which is the number of river basin runoff in Siberia, Russia, that had been counted. is Ivanov-Mezentsev index for climate biological productivity in case of potential evapotranspiration, which is estimated by $K_{y}$ humidity coefficient using Mezentsev method in formula (10). The climate biological productivity index value as categorized such as $0-8$ is biological productivity, which are very less, $8-12$ is less, $12-16$ is medium, 16-20 is relative high, and

\section{RESULTS}

\section{Heat supply}

The heat supply nessasary for plant growth is generally quite sufficient in most parts of the Mongolian territory. Figure 2 shows the geographical distribution for sum of active if the value is higher than 20 , the biological productivity is high.

The humidity-dry climate condition was first were assessed by a Mongolian scientist B. Jambaajamts by proposing the dryness index [25]. We have used G. T. Selyaninov heathumidity coefficient for assessment basing on the following formula (HHC).

$$
H H C=\frac{\sum P_{V-V I I I \text { mounth }}}{0,1 \sum t_{>10^{\circ} \mathrm{C}}}
$$

The sum total of active temperature higher than $5^{\circ} \mathrm{C}$ as shown in the denominator of the formula could be $10^{\circ} \mathrm{C}$ in order to show general moisture supply [13].

The daily air temperature and precipitation data from 70 meteorological stations under the national observation network starting from 1961 to 2017 were used in this study. The estimation was done using the daily mean deficit humidity covering the period from 1975 to 2017. The observation began in 1975 when the observation was carried out 8 times every day. In the case of arable farming region, meteorological stations began observations in 1984, and the available date were used simultaneously.

temperature based on mean climate between 1981 and 2010 (climate norm suggested by WMO), where the daily mean air temperature is higher than $10^{\circ} \mathrm{C}$. 


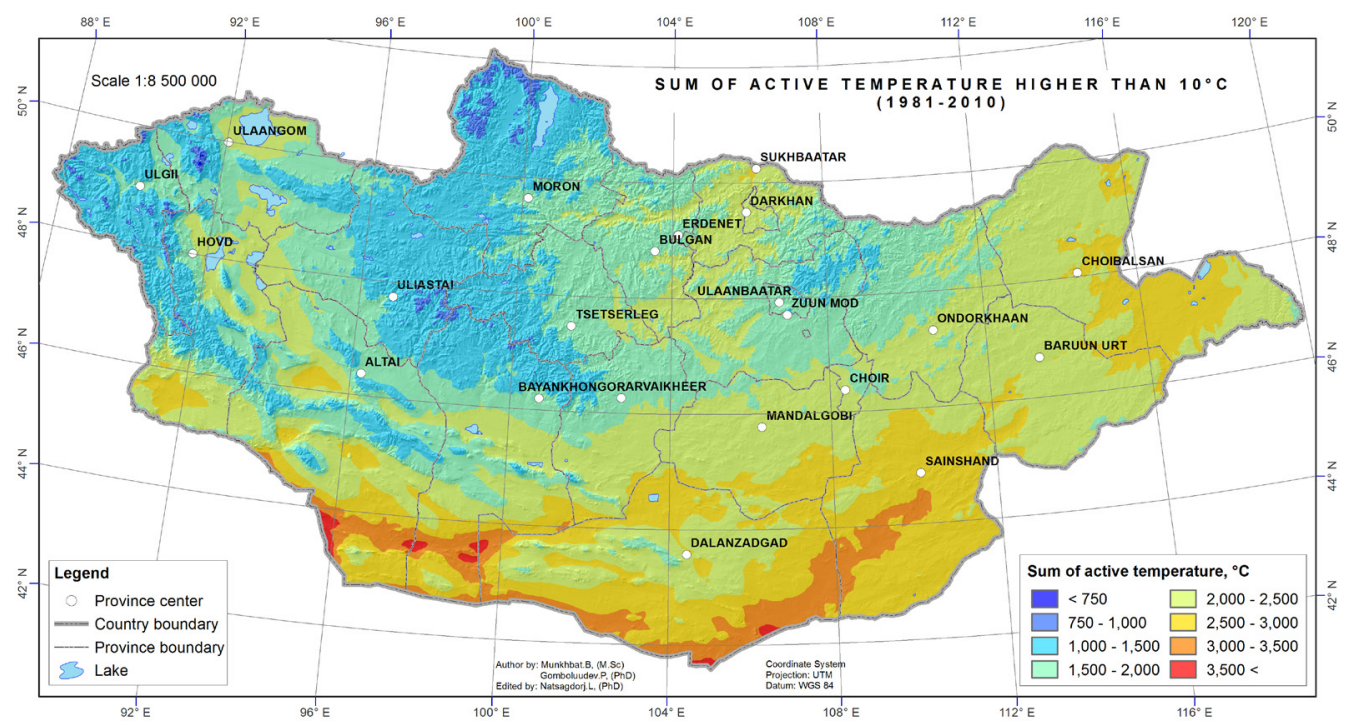

Figure 2. Geographical distribution for sum of active temperature higher than

(climate mean 1981-2010)

The key features of heat supply is shown in Table 2 including representive meteorological stations in the arable farming region. The daily mean temperature transfers through $5^{\circ} \mathrm{C}$ is in the third decade of April in spring and the first ten days in October in autumn for arable farming region. During this time, the active heat supply accumulated is from 1900 to 2400 degree Celsius. The daily mean temperature transfers through $10^{\circ} \mathrm{C}$ is in the second ten days of May in spring and also in the second decade of September in autumn, and respective accumulated heat supply is 1700-2100 degree Celsius during this period. As a matter of fact, the active heat demand for wheat is 1700$1900^{\circ} \mathrm{C}$ during its growing season.

Table 2. Main characteristics of heat supply in the arable farming region

\begin{tabular}{|c|c|c|c|c|c|c|c|c|c|c|c|}
\hline \multirow[t]{2}{*}{$\begin{array}{l}\text { Meteorologi- } \\
\text { cal stations }\end{array}$} & \multirow{2}{*}{ 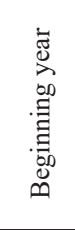 } & \multicolumn{2}{|c|}{$\begin{array}{c}\text { Date of } \\
\text { transfer } \\
\text { through } 5^{\circ} \mathrm{C}\end{array}$} & \multirow{2}{*}{ 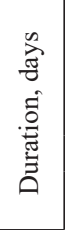 } & \multirow{2}{*}{$\begin{array}{l}\text { Sum of } \\
\text { active tem- } \\
\text { perature } \\
\qquad t_{>5^{\circ} \mathrm{C}}\end{array}$} & \multicolumn{2}{|c|}{$\begin{array}{c}\text { Date of } \\
\text { transfer } \\
\text { through } \\
10^{\circ} \mathrm{C}\end{array}$} & \multirow{2}{*}{ 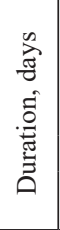 } & \multirow{2}{*}{$\begin{array}{l}\text { Sum of } \\
\text { active tem- } \\
\text { perature } \\
\qquad t_{>10^{\circ} \mathrm{C}}\end{array}$} & \multicolumn{2}{|c|}{$\begin{array}{l}\text { Sum of effective tem- } \\
\text { perature (degree days) }\end{array}$} \\
\hline & & start & end & & & start & end & & & $\sum t_{>5^{\circ} \mathrm{C}}$ & $\sum t_{>10^{\circ} \mathrm{C}}$ \\
\hline Sükhbaatar & 1966 & $4 / 24$ & $10 / 9$ & 168 & 2486 & $5 / 16$ & $9 / 19$ & 126 & 2157 & 1641 & 887 \\
\hline Yuroo & 1961 & $4 / 28$ & $9 / 30$ & 155 & 2260 & $5 / 18$ & $9 / 17$ & 122 & 2003 & 1480 & 772 \\
\hline Baruunturuu & 1961 & $4 / 27$ & $10 / 7$ & 164 & 2271 & $5 / 12$ & $9 / 18$ & 129 & 2020 & 1448 & 722 \\
\hline Dashbalbar & 1976 & $4 / 29$ & $10 / 4$ & 158 & 2330 & $5 / 17$ & $9 / 22$ & 128 & 2109 & 1535 & 816 \\
\hline Tarialan & 1963 & $4 / 24$ & $10 / 3$ & 163 & 2110 & $5 / 18$ & $9 / 14$ & 119 & 1785 & 1292 & 582 \\
\hline Darkhan & 1984 & $4 / 24$ & $10 / 6$ & 165 & 2472 & $5 / 14$ & $9 / 22$ & 130 & 2201 & 1643 & 888 \\
\hline Khutag & 1962 & $4 / 22$ & $10 / 6$ & 170 & 2333 & $5 / 12$ & $9 / 18$ & 129 & 2050 & 1476 & 744 \\
\hline Orkhon & 1969 & $4 / 23$ & $10 / 6$ & 163 & 2403 & $5 / 15$ & $9 / 20$ & 128 & 2126 & 1581 & 839 \\
\hline Dadal & 1961 & $4 / 28$ & $10 / 1$ & 156 & 2114 & $5 / 19$ & $9 / 16$ & 120 & 1843 & 1329 & 629 \\
\hline
\end{tabular}




\begin{tabular}{|l|c|c|c|c|c|c|c|c|c|c|c|}
\hline Erdenet & 1974 & $4 / 29$ & $10 / 4$ & 158 & 2034 & $5 / 20$ & $9 / 16$ & 116 & 1713 & 1240 & 542 \\
\hline Baruunkharaa & 1961 & $4 / 25$ & $10 / 7$ & 164 & 2439 & $5 / 14$ & $9 / 24$ & 131 & 2182 & 1611 & 859 \\
\hline Bulgan & 1961 & $5 / 1$ & $9 / 30$ & 151 & 1965 & $5 / 20$ & $9 / 11$ & 114 & 1691 & 1205 & 538 \\
\hline Binder & 1961 & $4 / 27$ & $10 / 2$ & 158 & 2155 & $5 / 18$ & $9 / 14$ & 120 & 1864 & 1361 & 658 \\
\hline Erdenemandal & 1964 & $4 / 29$ & $9 / 30$ & 154 & 1892 & $5 / 24$ & $9 / 11$ & 110 & 1546 & 1117 & 437 \\
\hline Ugtaal & 1980 & $5 / 1$ & $10 / 4$ & 156 & 2180 & $5 / 21$ & $9 / 21$ & 124 & 1919 & 1395 & 673 \\
\hline Khalkhgol & 1961 & $4 / 24$ & $10 / 7$ & 166 & 2521 & $5 / 15$ & $9 / 22$ & 130 & 2256 & 1689 & 944 \\
\hline Ondorkhaan & 1961 & $4 / 24$ & $10 / 5$ & 164 & 2413 & $5 / 15$ & $9 / 22$ & 130 & 2160 & 1589 & 846 \\
\hline Erdenesant & 1962 & $4 / 30$ & $10 / 7$ & 161 & 2234 & $5 / 18$ & $9 / 24$ & 129 & 1979 & 1424 & 681 \\
\hline
\end{tabular}

The heat resource during the growing season is increasing given global warming (Table 3). According to long-term time data of meteorological stations, active temperature higher than $10^{\circ} \mathrm{C}$ has increased by $80-90^{\circ} \mathrm{C}$ and in the last 10 years the acceleration was noticeable from 1961 to 2016, while the duration of active and effective temperature higher than $5^{\circ} \mathrm{C}$ and $10^{\circ} \mathrm{C}$ increase by 3 weeks. This trend tells us that the daily temperature transfer through $10^{\circ} \mathrm{C}$ in spring is coming 12 days earlier than normal, while the delay is by 13 days in autumn. This gives us the opportunity to extend arable farming development in Mongolia, however, poor moisture supply, owing to less precipitation, continues to remain the key limitations and barriers.

Table 3. Change of heat resource during growing season in arable farming region

\begin{tabular}{|l|c|c|c|c|c|c|}
\hline \multirow{2}{*}{$\begin{array}{c}\text { Meteorological } \\
\text { stations }\end{array}$} & \multirow{2}{*}{ Data period } & \multicolumn{2}{c|}{$\begin{array}{c}\text { Date of transfer } \\
\text { through } 10^{\circ} \mathrm{C}\end{array}$} & \multirow{2}{*}{ duration } & \multicolumn{2}{c|}{ Sum of temperature } \\
\cline { 3 - 4 } \cline { 6 - 7 } & & spring & autimn & & $t_{>5^{\circ} \mathrm{C}}$ & $t_{>10^{\circ} \mathrm{C}}$ \\
\hline Sükhbaatar & $1966-2016$ & -0.27 & 0.06 & 0.33 & 8.05 & 8.79 \\
\hline Yuroo & $1961-2016$ & -0.17 & 0.19 & 0.36 & 8.29 & 8.61 \\
\hline Baruunturuu & $1961-2016$ & -0.27 & 0.19 & 0.47 & 9.36 & 9.99 \\
\hline Dashbalbar & $1976-2016$ & -0.35 & 0.13 & 0.48 & 10.35 & 12.08 \\
\hline Tarialan & $1963-2016$ & -0.17 & 0.32 & 0.50 & 8.18 & 9.75 \\
\hline Darkhan & $1984-2016$ & -0.35 & 0.09 & 0.44 & 19.81 & 16.87 \\
\hline Khutag & $1962-2016$ & -0.31 & 0.09 & 0.40 & 7.66 & 8.58 \\
\hline Orkhon & $1969-2016$ & -0.17 & 0.21 & 0.38 & 10.49 & 9.87 \\
\hline Dadal & $1961-2016$ & -0.24 & 0.32 & 0.56 & 8.56 & 10.52 \\
\hline Erdenet & $1974-2016$ & -0.38 & 0.35 & 0.73 & 11.18 & 13.82 \\
\hline Baruunkharaa & $1961-2016$ & -0.13 & 0.23 & 0.36 & 9.15 & 9.53 \\
\hline Bulgan & $1961-2016$ & -0.16 & 0.18 & 0.35 & 6.20 & 7.25 \\
\hline Binder & $1961-2016$ & -0.24 & 0.22 & 0.46 & 8.75 & 9.15 \\
\hline Erdenemandal & $1964-2016$ & -0.19 & 0.22 & 0.42 & 9.39 & 8.78 \\
\hline Ugtaal & $1980-2016$ & -0.06 & 0.15 & 0.21 & 12.14 & 10.11 \\
\hline Khalkhgol & $1961-2016$ & -0.21 & 0.09 & 0.30 & 6.19 & 6.89 \\
\hline Ondorkhaan & $1961-2016$ & -0.14 & 0.12 & 0.26 & 7.36 & 7.50 \\
\hline Erdenesant & $1962-2016$ & -0.30 & 0.35 & 0.65 & 8.98 & 12.05 \\
\hline
\end{tabular}

\section{Moisture supply}

Plant moisture supply is defined by precipitation, soil moisture resource, evapotranspiration (surface evaporation capacity) as well as different types of characteristics for humidity-dry climate condition. Figure 3-4 show the geographical distribution of heat-humidity coefficient during growing season in the period from 1981 to 2010 . 


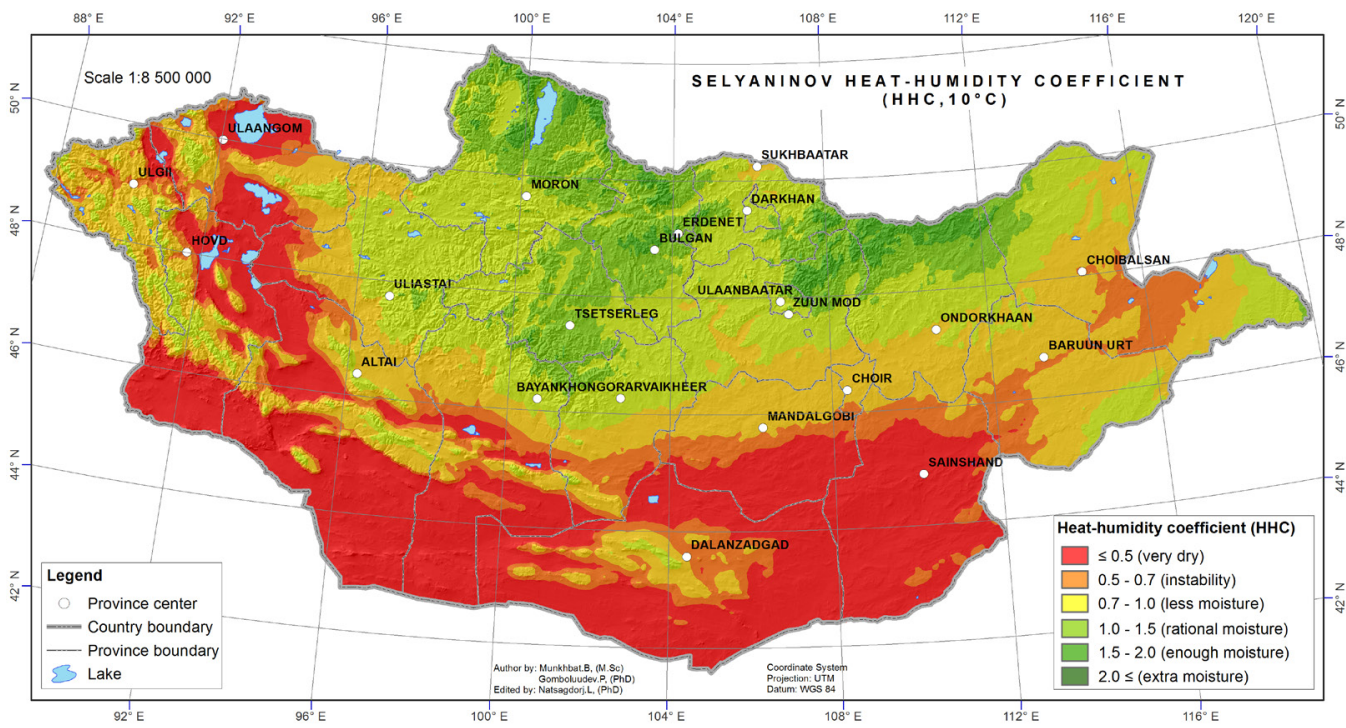

Figure 3. Geographical distribution of Selyaninov heat-humidity coefficient (sum of active temperature higher than)

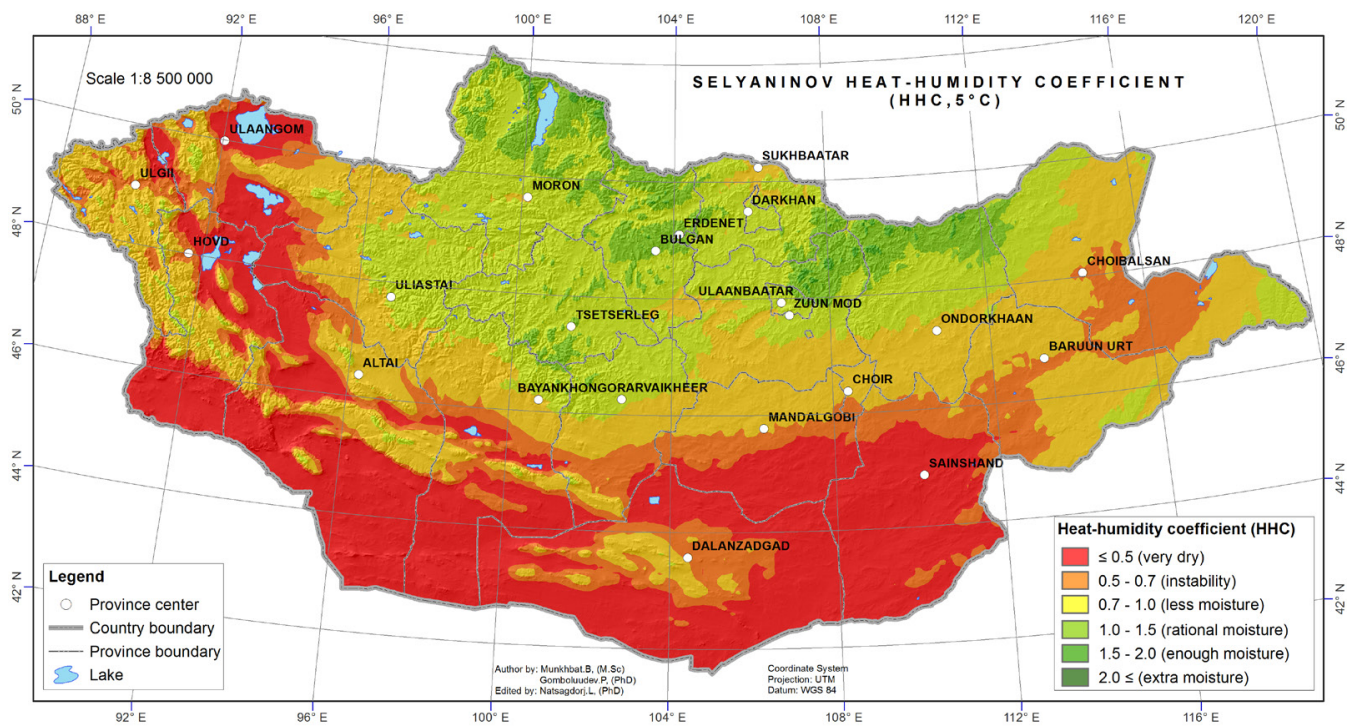

Figure 4. Geographical distribution of Selyaninov heat-humidity coefficient (sum of active temperature higher than)

According to G. T. Selyaninov categorization, the sum of active temperature higher than $10^{\circ} \mathrm{C}$, and the degree of humiditydry climate condition is divided as follows:

\footnotetext{
$\checkmark \quad$ HHC $\leq 0.3$ - very dry,$$
\checkmark \quad 0.3-0.5-\text { dry, }
$$ 
Also in terms of engagement of arable farming condition, it could be divided in the following manner:

$\checkmark \quad$ HHC $\leq 0.5$ - very dry in arable farming region with irrigation system,

$\checkmark \quad 0.7$ - instabile arable farming region,

$\checkmark \quad 1.0$ - Less moisture region,

$\checkmark \quad 1.5$ - Rational moisture region,

$\checkmark \quad H H C \geq 2.0$ - Extra moisture region.

The central arable farming region of

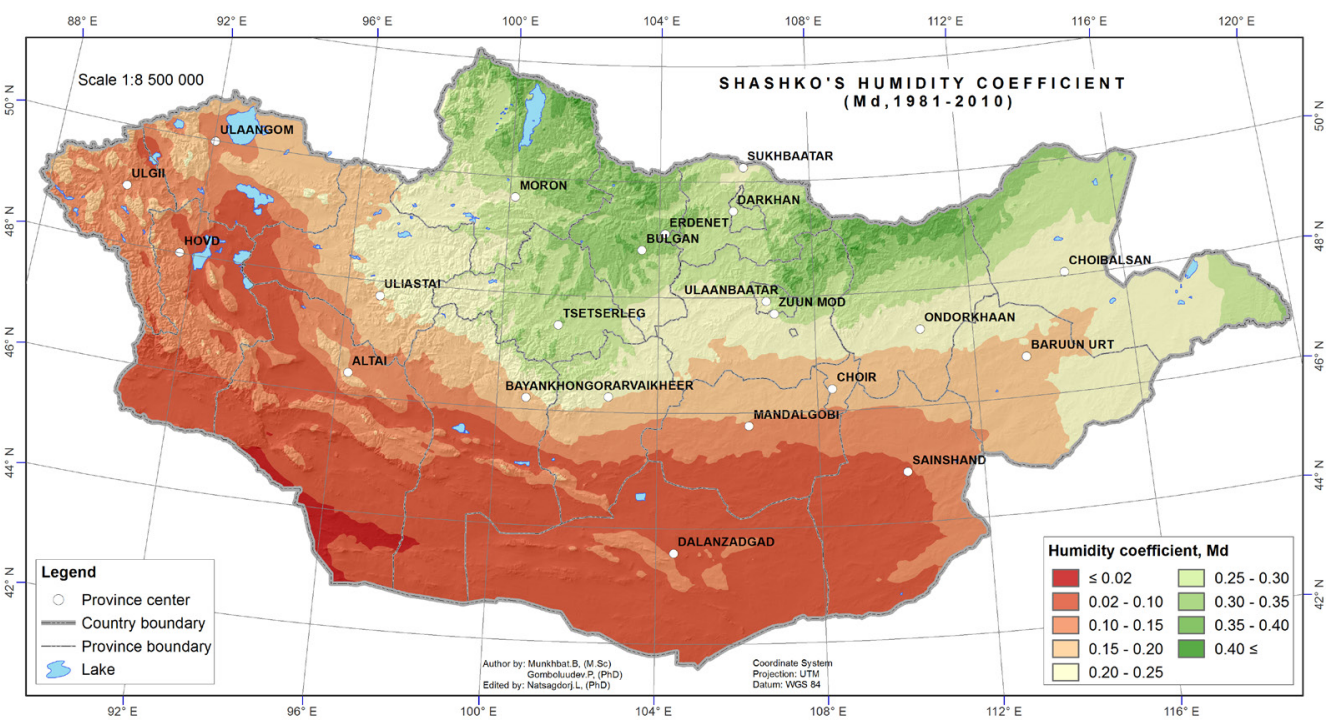

Figure 5. Geographical distribution of Shashko's humidity coefficient (),

(mean climate 1981-2010)

Some indicators of moisture supply in arable farming is shown in Table 4.

Table 4. Main indicators of moisture supply in arable farming, (mean climate 1981-2010)

\begin{tabular}{|l|c|c|c|c|c|c|c|}
\hline \multirow{2}{*}{\multicolumn{1}{c|}{ Station name }} & \multirow{2}{*}{$\begin{array}{c}P_{\text {V-VIII }} \\
\mathrm{mm}\end{array}$} & \multirow{2}{*}{$M_{d}$} & \multirow{2}{*}{$T K$} & \multirow{2}{*}{$D I^{*}$} & \multicolumn{4}{c|}{$H H C$} \\
\hline Sukhbaatar & 215 & 0.20 & 8.25 & 5.66 & 1.01 & 1.00 & -0.10 \\
\hline Yuroo & 211 & 0.20 & 7.52 & 5.62 & 0.99 & 1.07 & -0.10 \\
\hline Baruunturuu & 166 & 0.16 & 7.00 & 7.87 & 0.85 & 0.86 & -0.04 \\
\hline Dashbalbar*** & 225 & 0.26 & 8.10 & 5.49 & 1.09 & 1.12 & -0.16 \\
\hline Tarialan & 252 & 0.28 & 8.02 & 3.84 & 1.34 & 1.32 & -0.12 \\
\hline Darkhan*** & 236 & 0.26 & 9.45 & 4.24 & 1.1 & 1.12 & -0.07 \\
\hline Khutag & 247 & 0.28 & 8.68 & 3.95 & 1.22 & 1.19 & -0.10 \\
\hline Orkhon*** & 234 & 0.24 & 8.65 & 5.05 & 1.13 & 1.13 & -0.07 \\
\hline Dadal & 299 & 0.32 & 10.69 & 3.82 & 1.54 & 1.66 & -0.12 \\
\hline
\end{tabular}




\begin{tabular}{|l|c|c|c|c|c|c|c|}
\hline Erdenet*** & 272 & 0.32 & 9.26 & 3.56 & 1.66 & 1.54 & -0.18 \\
\hline Baruunkharaa & 224 & 0.20 & 8.58 & 5.79 & 1.22 & 0.86 & -0.09 \\
\hline Bulgan & 271 & 0.37 & 8.60 & 3.26 & 1.55 & 1.57 & -0.09 \\
\hline Bunder & 252 & 0.26 & 8.64 & 4.66 & 1.29 & 1.36 & -0.09 \\
\hline Erdenemandal & 238 & 0.33 & 6.88 & 3.44 & 1.47 & 1.39 & -0.18 \\
\hline Ugtaal*** & 213 & 0.24 & 7.54 & 5.23 & 1.16 & 1.14 & -0.07 \\
\hline Khalkhgol & 224 & 0.20 & 8.65 & 7.09 & 1.13 & 1.00 & -0.03 \\
\hline Ondöokhaan & 184 & 0.16 & 6.83 & 7.88 & 0.87 & 0.88 & -0.07 \\
\hline Erdenesant & 198 & 0.21 & 7.03 & 6.28 & 0.94 & 1.02 & -0.11 \\
\hline
\end{tabular}

(the ratio between sum of deficit humidity and precipitation in May-August). **- HHC value is coeffiecent of linear regression in 1961-2017 is multiplied by 10, ***-meteorological stations, which trends are defined by data since 1976.

Although plant heat supply is increasing on the backdrop of global climate warming, moisture supply is not increasing to the desired level and according to climate change projections, it would not increase either, which could likely make it much more complicated for developing argiculture in the country [26]. Figure 5 shows long-term trends (1961-2017) of precipitation, according to Selyaninov heat-humidity coefficient and Shashko's humidity coefficient from May to August at Baruunkharaa station.
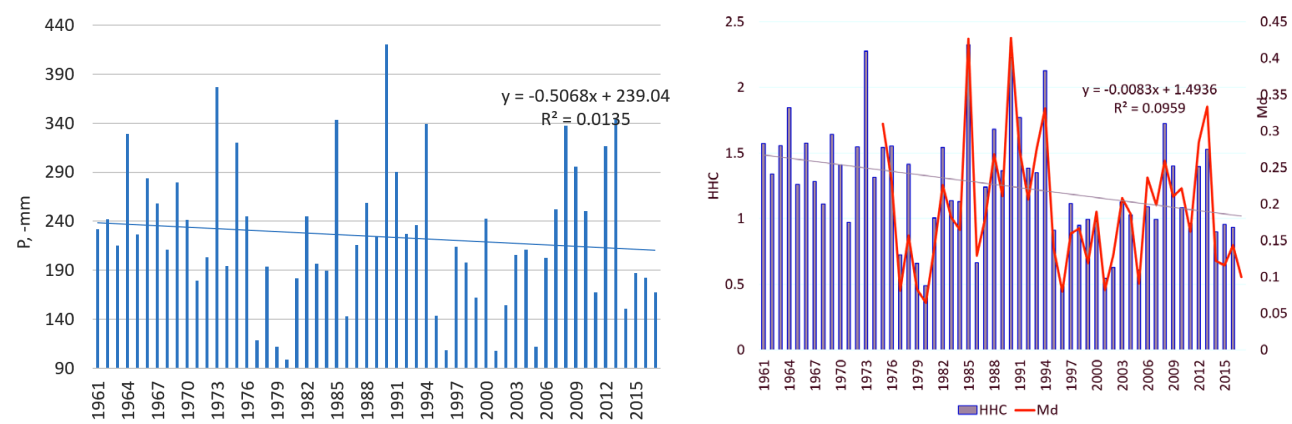

Figure 6. Long-term trends of precpitation according to Selyaninov heat-humidity coefficient and Shashko's humidity coefficient at Baruunkharaa station

Simular trends are typical for central, eastern and western arable farming regions of Mongolia. Moreover, precipitation variance coefficient is increasing in the eastern region, which is one of the restrictive factors in plant growing [27]. Here, linear correlation coefficient is 0.92 between $\mathrm{HHC}$ and $M_{d}$. From the figure, precipitation at Baruunkharaa station during the growing season is decreasing with an acceleration rate of $5 \mathrm{~mm} / 10$ years. The $\mathrm{HHC}$ value was 1.5 units during the $1960 \mathrm{~s}$, which dropped to 1.0 units by the end of the time period.

\section{Asessment of climate biocapacity}

Heat supply during plant growing season is generally sufficient in Mongolia, however, precipitation amount do not exceede $300 \mathrm{~mm}$ in the arable farming regions, which revolves around $200 \mathrm{~mm}$ in most of these regions. Therefore, moisture deficit is the main barrier and limitation. On the other hand, the type of 
summer precipitation is changing rapidly. The weight of convective precipitation, which falls with high intensity covering a relatively small area and within a short duration of time, is increasing in the total precipitation. This also has a negative impact on agriculture [27].

Table 5. Indicators of climate biocapacity

\begin{tabular}{|l|c|c|c|c|c|c|c|}
\hline Station name & $\mathbf{C B C}_{\mathbf{1 9 0 0}}$ & $\mathbf{a}^{* 10}$ & $\mathbf{C B C}_{\mathbf{1 0 0 0}}$ & $\mathbf{B}_{\mathbf{C 1 9 0 0}}$ & $\mathbf{5 5}^{*} \mathbf{C B C}_{\mathbf{1 0 0 0}}$ & $\mathbf{B}_{\mathbf{C}}$ & $\mathbf{C}_{\mathbf{B}}$ \\
\hline Sukhbaatar & 0.65 & +0.02 & 1.23 & 65 & 68 & 8.1 & 24 \\
\hline Yüroo & 0.61 & +0.02 & 1.16 & 61 & 64 & 7.7 & 23 \\
\hline Baruunturuun & 0.46 & -0.02 & 0.87 & 46 & 48 & 5.4 & 18.9 \\
\hline Dashbalbar & 0.70 & -0.03 & 1.33 & 70 & 73 & 12.3 & 22.5 \\
\hline Tarialan & 0.68 & +0.04 & 1.29 & 68 & 71 & 10.7 & 25 \\
\hline Darkhan* & 0.80 & +0.05 & 1.51 & 80 & 83 & 11.9 & 25.6 \\
\hline Khutag & 0.78 & +0.01 & 1.47 & 78 & 81 & 12.1 & 26.2 \\
\hline Orkhon* & 0.70 & +0.02 & 1.33 & 70 & 73 & 10.3 & 24.8 \\
\hline Dadal & 0.72 & -0.001 & 1.37 & 72 & 76 & 12.3 & 27.2 \\
\hline Erdenet* & 0.69 & +0.03 & 1.30 & 69 & 72 & 11.6 & 24.3 \\
\hline Baruunkharaa & 0.65 & +0.04 & 1.23 & 65 & 68 & 8.2 & 24.2 \\
\hline Bulgan & 0.72 & +0.05 & 1.36 & 72 & 75 & 13.1 & 24.8 \\
\hline Binder & 0.66 & -0.02 & 1.25 & 66 & 69 & 10.5 & 24.8 \\
\hline Erdenemandal & 0.64 & +0.01 & 1.21 & 64 & 66 & 11 & 21.7 \\
\hline Ugtaal* & 0.62 & -0.02 & 1.17 & 62 & 64 & 8.6 & 23 \\
\hline Khalkhgol & 0.63 & +0.04 & 1.20 & 63 & 66 & 10 & 23.8 \\
\hline Ondorkhaan & 0.49 & -0.04 & 0.93 & 49 & 51 & 5.8 & 20.4 \\
\hline Erdenesant & 0.57 & -0.02 & 1.08 & 57 & 59 & 7.7 & 21.9 \\
\hline Note: CBC & $0 f(17)$ &
\end{tabular}

Note: $C B C_{1900^{-}}$sum of temperature threshold value of 1900 in denominator of Formula (4), $a^{*} 10$ - the linear regression coefficient of $C B C_{1900}$ between 1975 and 2016 is multiplied by $10, C B C_{1000}$ - the value set up threshold value 1000 in denominator of Formula (4), $B C_{1900}$ - the value set up threshold value 1900 in denominator of Formula (7), $55{ }^{*} C B C_{1000}$ - estimated by Formula (7) as respectively. $B_{C}$ - estimated by Formula (1) and $\varepsilon$ in Formula (2) is selected by Shashko's, $M_{d}, C R_{B}$-agricultural climate rating estimated by Formula (1), which is precipitation in May-June in nominator of Formula (3) is multiplied by 1 and 4, August precipitation is multiplied by 0.3 and July precipitation is taken as original value respectively, * - meteorological station has short time series.

The climate biocapacity value in arable farming region of Mongolia is less than 0.8, and the rating score is higher than 40 in total. But there are almost no areas where the climate bio productivity corresponds to medium category. On the other hand, this means that the country is not a convenient or very convenient region for undertaking arable farming without irrigation. However, this indicator is $445-448$ points higher in Zaire and Brazil, 86-118 in Ireland, Denmark, Switzerland and the former now independent republics, which were formely part of the Soviet Union, and Canada in cold climate region in mid-latitude.

The geographical distribution of climate bio productivity, which is expressed by IvanovMezentsev index TK, is shown in Figure 7. 


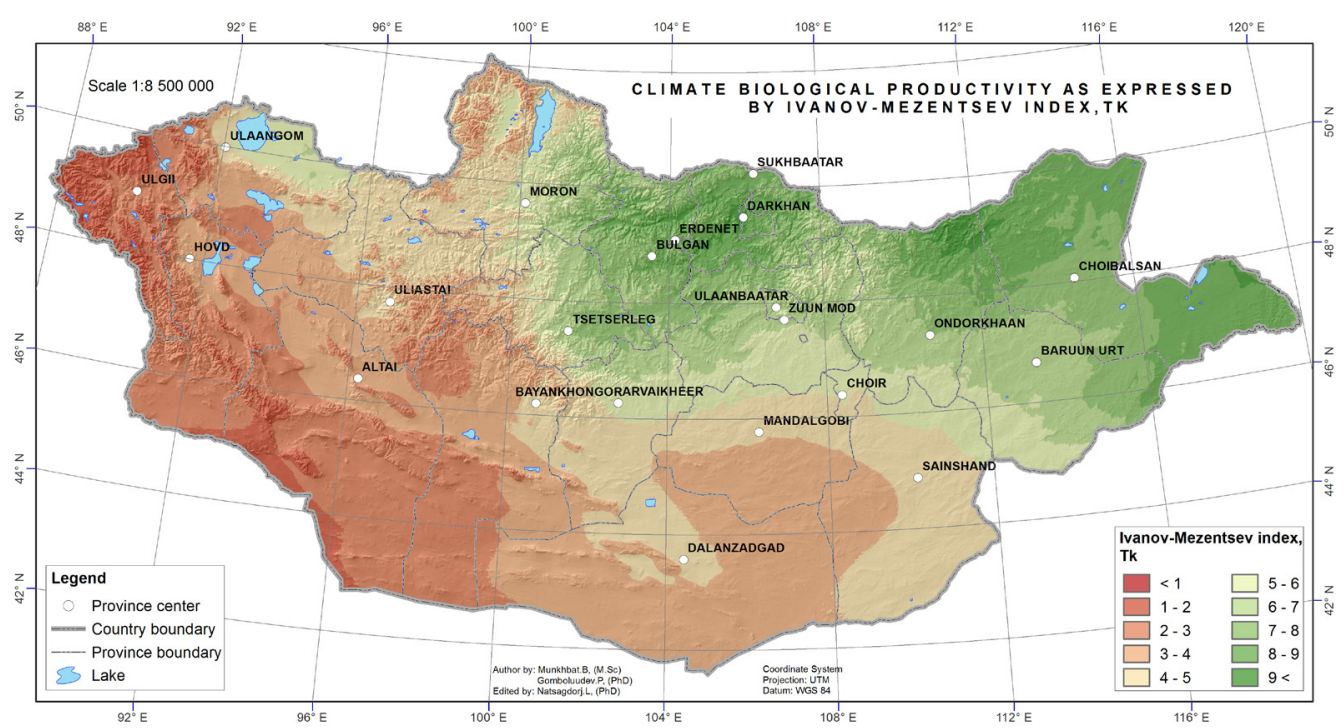

Figure 7. Climate biological productivity as expressed by Ivanov-Mezentsev index

The CBC must show relationship between climate resource and land productivity. We found high correlation between M. I. Budyko radiation dryness index and summer mean pasture yield in the fenced areas, which are protected against the negative impacts of livestock grazing [28]. Also climate biological productivity of Ivanov-Mezentsev and Selyanov heat-humidity indices have high correlation with summer pasture yield as well. Figure 8 shows the relation between the CBC and summer mean pasture yield, which were measured at 70 meteorological stations in different natural zones of Mongolia.

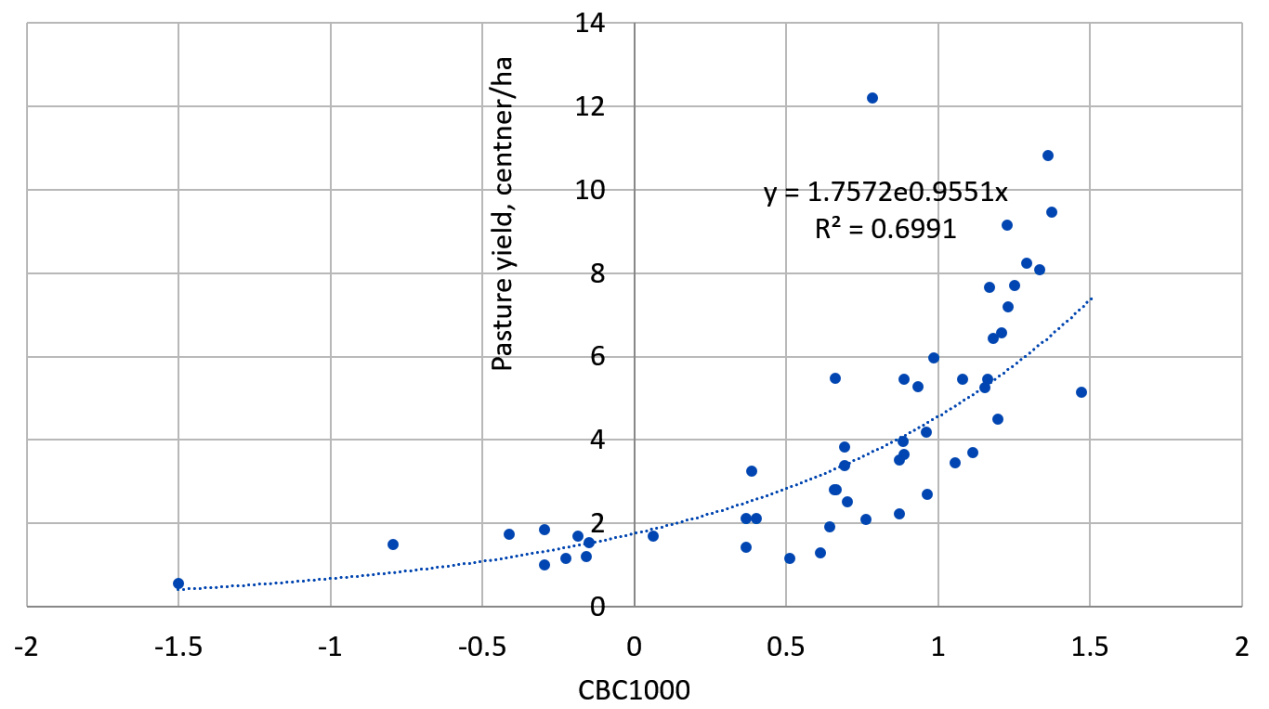

Figure 8. Relationship between climate biocapacity and summer mean pasture yield, 1981-2015 
Natural logarithm is used to estimate $K_{\mathrm{p}}$, hence, the $\mathrm{CBC}$ takes negative value when $M_{d}$ 's is small. Therefore, Shashko's method is not appropriate for very dry climate region. On the other hand, the CBC was initially intended to be used for assessing climate conditions for crops, and consequently, it is not consistent with high pasture yield in area, which is humid and does not have enough heat supply. Special point (the $\mathrm{CBC}$ is 0.78 and yield exceeds 12 centner/ha) in the figure corresponds to the Renchinlkhümbe meteorological station,

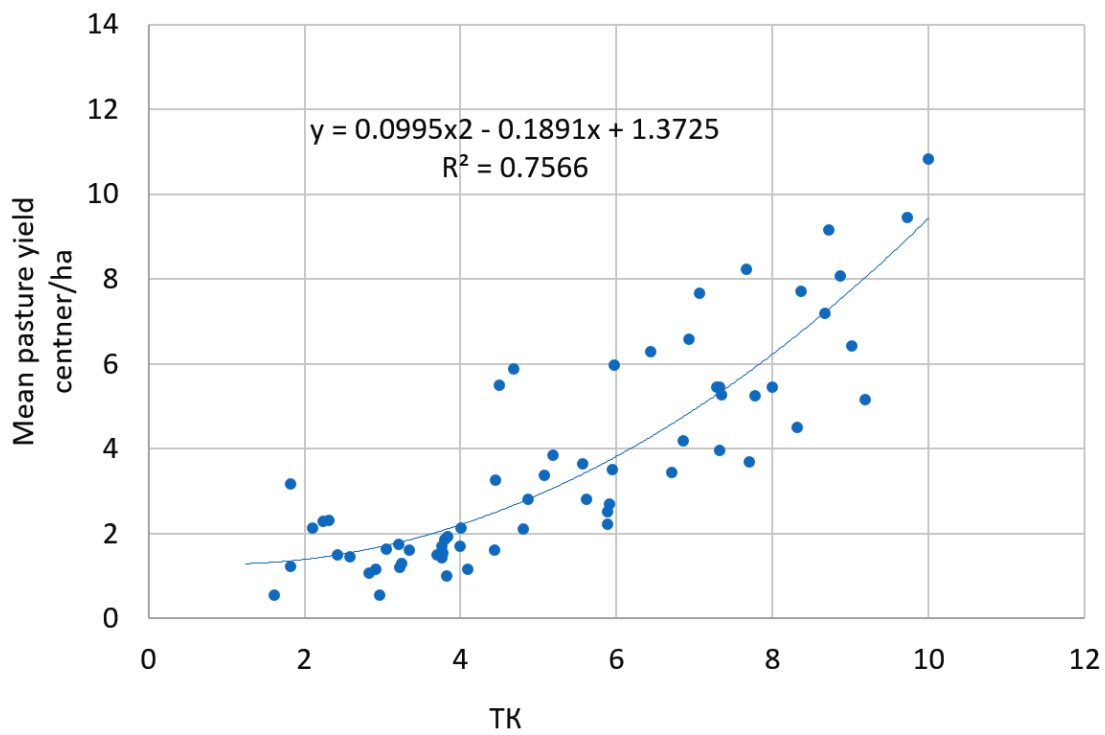

Figure 9. The relationship between summer mean pasture yield in fenced areas and CBC of IvanovMezentsev index

The CBC shows yield amount with certain level of heat-humidity condition [13] in the given local area. Even though it is a nomogram, it has been done for finding climate rating score in local area and crop yield based on Shashko's humidity coefficient $\left(M_{d}\right)$ and sum of active temperature higher than $10^{\circ} \mathrm{C}[29]$.

In Table $4, \mathrm{~B}_{\mathrm{C}}$ and $C R_{\mathrm{B}}$ are shown simultaneously, from where it can be which has less heat supply in Darkhad depression. The relationship between $\mathrm{CBC}$ and mean summer pasture yield reached 0.84 , an indicator that the relation is high $(r=0.80)$ between Budyko radiation dryness index and pasture yield. However, relation between the climate bio productivity of Ivanov-Mezentsev index TK and pasture yield did not reach the appropriate level $(r=0.87)$. The relation between TK and summer mean pasture yield is shown in Figure 9. 


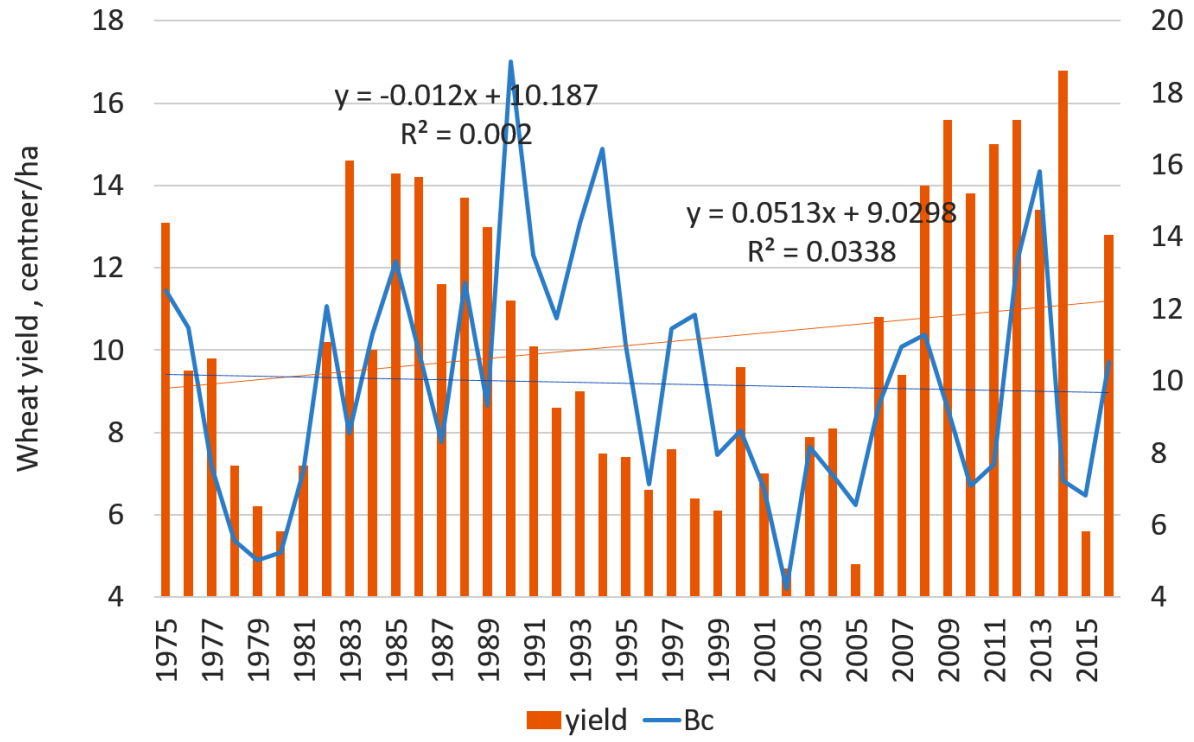

Figure 10. Inter-annual change of $C B C$ and mean wheat yield

Linear correlation coefficient between $\mathrm{CBC}$ and the national average yield of wheat is 0.42 , which is lower than the relation between pasture yield and heat-humidity coefficient. This means that crop yield in a particular year does not depend on heat-humidity condition alone, but also depends on extreme weather conditions such as soil moisture during seeding period, summer hot wave, freeze, thunder and

\section{CONCLUSIONS}

We have assessed climate biocapacity and considered its present trend within this research study. Based on the research results, the following conclusions can be drawn:

1. Heat supply is increasing during the growing season. The sum of active temperature during growing season is increasing by $80-90^{\circ} \mathrm{C}$ every 10 years and the angle of coefficient of linear regression trend was 400 500 degree Celsius in the last 56 years. The daily temperature transfer through $10^{\circ} \mathrm{C}$ started setting in 12 days earlier in spring, while there has been a delay of up to 13 days in autumn starting from 1961 to 2016. This finding can help us select and plant crops which have long hail, and precipitation allocation during the growing season etc., and furthermore, technical level of actual condition has a high impact on arable farming. From the figure, we can see the different behavior of yield per hectare, which has been decreasing due to weakening of the CBC since 1975 and increasing due to renewed arable farming sectors since 2008 within the "Atar Ayan-3" program.

growing season.

2. According to different indicators of trends of plant moisture supply indices (Shashko's humidity coefficient, Selyaninov's heat-moisture coefficient, B. Jambaajamts dryness index etc.) since 1961 dryness has been persisting in Mongolia. For example, the $\mathrm{HHC}$ value, which is representative of arable farming region near Baruunkharaa station, was 1.5 units the $1960 \mathrm{~s}$ and had decreased to 1.0 units at the end of the period. On the one hand, heat supply of vegetation is increasing, but on the other hand, moisture supply, which is the main factor limiting crop yield, is far below the required level and this situation may 
deteriorate further in the years ahead.

3. The climate biocapacity (CBC) indicator and Ivanov-Mezentsev climate biological productivity index have high correlation with summer mean pasture yield at meteorological stations in different natural zones. They could be easily used in different types of agrometeorological, landscape and biographical classification.

4. According to assessment results of $\mathrm{CBC}$ using D. I. Shashko's method, rating score is 40-83 in arable farming region of Mongolia, which is an indication that climate biological productivity comes under "low" to "slightly low" category. There is no detecting "medium" category. This shows that arable farming without irrigation is risky in Mongolia as well.

5. The $\mathrm{CBC}$ is decreasing in the central part of the arable farming region owing to the ongoing climate change. This means means that vegetation heat supply is going to increase, although the key crop yield limitation is associated with decreasing of moisture supply.

\section{REFERENCES}

1. Kolosov, P. I. (1971). Climate factor in agriculture and agroclimate zone-L., Hydrometeoizdat., p. 328.

2. Sapojnikova, S. A. (1979). Experiment of integrated agricultural assessment in climate territory of socialist country in Europe (Agroclimate zone for five basic agricultural cultures in territory of socialist country in Europe) - Sofya, Izd. Bulgaria AN, pp. 99-120.

3. Shashko, D. I. (1985). Agroclimate resource of USSR - M.: Hydrometeizdat, p. 243.

4. Gordyev, A.V., Kleshenko A.D., Chernyakov B.A., Sirotenko O.D. (2006). Potential bioclimate in Russia: theory and practice. M.: T-vo KMK scientific publishing, p. 512.

5. Sirotenko, O. D., Abashina E. V. (1982). Application of dynamic model for agrometeorological condition of crop yield. Meteorology and hydrology, № 6, pp. 95-101.

6. Ivanov, N. N. (1948). Landscape-climatological zones in world. M. L. 1948. S. 117 (Paper of Geography, New volume; T.1.).

7. Ivanov, N. N. (1962). Indicators of biological effectivity for climate. (N. N. Ivanov). Izv. VGO. T. 94. Vol.1. pp. 65-70.

8. Mezentsev, V. S. (1973) Water balance. Novosibirsk, p. 229.

9. Shubin, V. F. (1953). Land cultivation of the Mongolian People's Republic. Proceedings of Mongolian Commission, Vol. 52. M.

10. Davaajav, B. (2017). Land cultivation development of Mongolia in 2 the $0^{\text {th }}$ century. Letter of Altai National University. DOI 10.14258/izvasu (2017). pp. 5-21.

11. Jambaajamts, B. (1970). Climate classification for agriculture in territory of Republic of Mongolia (PhD dissertation of Geography). Leningrad.

12. Atlas of climate and surface water of the Mongolian People's Republic (1987). M., izd. Industry № 10. GUGK USSR. p. 160.

13. Agricultural climate reference of Mongolia. (B. Jambaajamts, S. Sangidansranjav). 1977. Photooffset publishing. Hydrometeo.inst. p. 102.

14. Agricultural climate resource reference of Mongolia. (Sh. Bayasgalan, D. Dagvadorj). 1996. UB. Photo-offset publishing. Hydrometeo.inst.

15. National atlas of Mongolia (D. Dorjgotov). 2009. UB,

16. Sangidansranjav., S. Dagvadorj D. (1985). Application of dynamic-statistical model for forecasting of cereal yield in Mongolia's conditions. Proceedings of Institute of Meteorology and Hydrology. № 10. pp. 115-125.

17. Dagvadorj, D. (1988). Applied dynamic-statistical model for cereal yield in the Mongolian People’s Republic. L., Dep. VNIGMI-MTsD., № 837, GM-88.

18. Sangidansranjav, S., Bayasgalan, Sh., Erdenetsetseg, D. (1989). Appilcation of "Weather-yield" dynamic - statistical model in some agrometeorological task. Symposium proceedings, 1989-1117, UB., Minister of Nature and Environment, pp. 65-74. 
19. Bayarmaa, B. (2015). Agroclimate resources and their impact on yield (western soum of Selenge aimag, Mongolia). National University of Western Tomsk, № 399, DOI:10.17223/15617793/399/3.9

20. Munkhdulam, O., Avirmed, E., Sainbayar, D. (2017). Assessment of bioclimate capacity of Mongolia based on satellite and ground meteorological observation. News of Science Academy, Vol. 57, No. 3 (223), pp. 5-20.

21. Jambaajamts, B. (1984). Agroclimate resource of Mongolia. UB, UKhG, pp. 9, 75.

22. Afonin, A .N., Grin, S. L., Dzubenko, N. I., Frolov, A. N. (2008). Agroecological atlas of Russia and neighbouring country: economical valueble plant, their pests, deaseas and weed plant [DVDversion]. http://www.agroatlas.ru.

23. Mongolia's Third National Communication to the United Nations Framework Convention on Climate Change 2018.

24. MARCC 2014. Mongolia assessment report on climate change - 2014, MNET Ulaanbaatar.

25. Natsagdorj, L., Altantsetseg, Kh. (2008). Prelimnary result of duration change of summer precipitation over territory of Mongolia. Proceedings of "Climate change of westsern region" workshop.

26. Natsagdorj, L. (2012): Toward trends of annual productivity depending on present climate change. News of Science Academy, Vol. 52, № 3 (203). pp. 24-30.

27. Mishenko, Z. A. Agroclimate. Odessa. 2006. p. 540. 